\title{
Evidence for a Sympatric Origin of Ribolla gialla, Gouais Blanc and Schiava cultivars ( $V$. vinifera $\mathrm{L}$.)
}

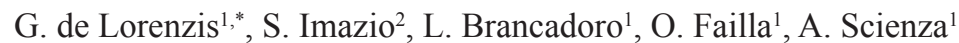

(1) Dipartimento di Scienze Agrarie e Ambientali - Università degli Studi di Milano, via Celoria 2, 20133 Milano, Italy

(2) Dipartimento di Scienze Agrarie e degli Alimenti - Università degli Studi di Modena e Reggio Emilia, via Amendola, 2, Padiglione Besta, 42122 Reggio Emilia, Italy

Submitted for publication: November 2013

Accepted for publication: January 2014

Key words: Fingerprinting, geographical origin, relationship, SSR, Vitis vinifera

\begin{abstract}
Ribolla gialla is an autochthonous grape variety cultivated in Friuli Venezia Giulia (Italy) and in Slovenia, and probably originated in Eastern Central Europe. Just like Ribolla gialla, the Gouais blanc and Schiava cultivars also appear to have originated in the same geographical area. To verify this hypothesis, a pool of varieties probably sharing the same historical and geographical origin were taken into account. The fingerprinting, by 35 SSR loci, of Gouais blanc, Ribolla gialla, Schiava grossa and Schiava lombarda (synonyms of Schiava bresciana), is presented and the correlation among historical, geographical and genetic information of these cultivars was investigated. Gouais blanc and Traminer, already suggested as key varieties in the development of European grape diversity and as parents for some French varieties, interestingly enough seems to be linked to Ribolla gialla. The putative parentage was verified using 58 microsatellite markers. The genetic results suggest a common geographical origin for Gouais blanc, Ribolla gialla and the Schiava group: these cultivars appear to be related through sympatric origin. The hypothesis of Ribolla gialla as a progeny of Gouais blanc and Traminer was ruled out. The data proved a second-degree relationship between Gouais blanc and Ribolla gialla and a third or more distant degree of relationships between Ribolla gialla and Traminer.
\end{abstract}

\section{INTRODUCTION}

It is largely documented that the original sites of domestication of wine and table cultivars of Vitis vinifera L. are in western Asia, most likely in eastern Anatolia and the Caucasian region (Olmo, 1995; Zohary \& Hopf, 2000; This et al., 2006a). From the first centres of domestication, the cultivated grapevines moved towards Europe, possible through secondary centres of domestication, following the ancient routes of civilisation (Forni, 2012). The result of the primary and secondary domestication events, and successive local breeding processes, was the huge genetic variability of grapevine varieties, which are widespread in all the traditional winemaking areas, forming a rich germplasm diversity. Commencing from the first decade of the last century, as a consequence of the massive replanting of European vineyards after the devastating attack of Phylloxera (Daktulosphaira vitifoliae Fitch, a homopteran insect introduced from North America at the end of nineteenth century), a significant part of these locally bred and grown varieties began to decline and progressively were substituted by a limited numbers of elite local and international cultivars.

Nowadays, projects aimed at the recovery and exploitation of cultivars with historical and geographical relevance are in progress in a number of viticultural regions. Ribolla gialla, a traditional variety of the Collio area (Gorizia province, North-Eastern Italy), is one such example. According to its microsatellite allelic profile, Ribolla gialla is identical to Rebula, a variety from the Slovenian winegrowing area of Brda, on the Italian border (Rusjan et al., 2010; De Lorenzis et al., 2013). Ribolla gialla is considered an ancient and traditional cultivar of these two neighbouring regions (Cosmo \& Polsinelli, 1957), with a strong relationship with their terroirs (Calò et al., 2006). In Italy, the first documented evidence of a wine made from Ribolla gialla dates back to 1409 , when, during a banquet in honour of Pope Gregory XII, Ribolla wine from the Rosazzo Abbey was served (Peterlunger et al., 2004). The historical importance of this variety is traceable through the centuries in its usage in the Collio area: for example, Ribolla gialla was offered by municipal authorities to welcome foreign representatives or illustrious visitors, and supplied to the rich Venetian Republic markets (Calò \& Costacurta, 2004). In the past few decades it was used to produce wines aimed

*Corresponding author: Gabriella de Lorenzis, e-mail address: gabriella.delorenzis@unimi.it [Tel.: +3902 50316556; fax+3902 50316553] Aknowledgements: The research was done in the framework of the project "MIGLIORVITE", funded by the Agriculture Department of Lombardy Region, Italy. The research was also co-funded by Cantina Produttori Cormons. The authors wish to thank Dr José Vouillamoz from Agroscope (Switzerland), for providing the Gouais blanc variety, and Dr Stella Grando from Fondazione Edmund Mach (Italy), for technical support 
at the local markets and appreciated by consumers for their typicality; now, Ribolla gialla grapes are back in vogue due to the growing interest in traditional and local grapevine landraces.

In the framework of the exploitation of local germplasm, the exploration of inter- and intravarietal genetic diversity is fundamental to define the most appropriated strategies. Some of these autochthonous grapevine varieties could have the same geographical origin (sympatry) and share important events in their cultural and economic history. This could be the case of Ribolla gialla, Gouais blanc, and the group of Italian cultivars called "Schiava".

Gouais blanc, or Heunisch weiss in German, is an old variety that was widespread all over Central Europe. It possibly was introduced from the Eastern Mediterranean Basin along the Danube route in East-Central Europe. It was brought to France by the Roman Emperor Probus during the $3^{\text {rd }}$ century AD as a gift to the Gauls from his Croatian homeland (Aeberhard, 2005). It was cultivated up to the modern age in Austria, France, Germany and Switzerland. In Italy, a few Gouais blanc plants have been identified in Valle d'Aosta and other mountain valleys of Piedmont, attesting to its likely cultivation in the north-west area of the Alps (Schneider \& Mannini, 2006). It is considered a qualitatively mediocre variety because of its vigour and high productivity; indeed, "Gouais" has a denigrating meaning, from the old French adjective "gou" (Bowers et al., 1999a). At present it is a neglected variety that is only maintained in germplasm collections. Nevertheless, it is a variety that is of paramount importance for the evolution of the West European $V$. vinifera varietal assortment, being the progenitor of several important varieties including the well-known Chardonnay and Gamay (Bowers et al., 1999a). Gouais blanc, together with Traminer and Pinot noir, have already been proposed as possible parents for several French varieties (Bowers et al., 2000).

Based on the molecular analysis of 2344 unique genotypes by 20 nuclear SSR, Lacombe et al. (2012) recently identified 63 genotypes (confirmed and new) related to Gouais blanc through a first-degree relationship, and among the kin group of half kinships the largest was the Gouais blanc kin group.

In Italy, the name "Schiava" (Schiava bianca, Schiava bresciana, Schiava gentile, Schiava grigia, Schiava grossa, Schiava lombarda, Schiava nostrana) is customary to identify a group of varieties possibly sharing some phenotypic traits, as well as a possible common geographical origin in Slavonia, a geographical and historical region in Eastern Croatia (Scienza \& Failla, 1996). These cultivars were widely cultivated in Lombardia, Veneto, Trentino Alto Adige and Friuli (Northern Italian regions). Schiava grossa is cultivated as Trollinger in Austria and Germany (Vouillamoz \& Arnold, 2010) and Tirolan in Croatia (E. Maletic, personal communication, 2014). It is supposed that the "Schiava" group arrived in Northern Italy and Germany from Pannonia (an ancient province of the Roman Empire bounded north and east by the Danube) with the Longobards, a Germanic population that invaded Italy in the eight century A.D. (Scienza \& Failla, 1996). In Italy, these varieties are still cultivated in Trentino Alto Adige and Lombardia, although they have been neglected for decades in the Veneto and Friuli regions (Cosmo \& Polsinelli, 1962). The generic varietal name Sclave has appeared in the Lombard notarial deeds since the $11^{\text {th }}$ century, and in the Venetian-Lombard region it definitely was the most frequently mentioned variety in land rental documents, in acts of donation and duties and in lease payments (Scienza, 1999). According to molecular analysis reported in Fossati et al. (2001), the Schiava accessions collected in the different cultivation areas were classified into two main genotypes: Schiava grossa and Schiava lombarda.

The aim of this work was to investigate the genetic relationship among Ribolla gialla, Gouais blanc and "Schiava" cultivars probably sharing a common historical and geographic origin, based on the results of 35 microsatellite markers (SSR). Moreover, Ribolla gialla as a potential progeny of Gouais Blanc and Traminer was investigated by deep genotyping (58 SSR loci). Nuclear simple sequence repeat (SSR) markers are a useful tool to determine the genetic diversity of $V$. vinifera cultivars (Cipriani et al., 2010; Laucou et al., 2011; Bacilieri et al., 2013; Imazio et al., 2013), to solve cases of homonyms (This et al., 2006a, 2006b) and synonyms, and to establish pedigree analysis (Bowers et al., 2000; Vouillamoz \& Grando, 2006; Boursiquot et al., 2009; Vouillamoz \& Arnold, 2010; De Lorenzis et al., 2012; Lacombe et al., 2012).

\section{MATERIALS AND METHODS \\ Plant material}

Accessions of Barbera, Bela Glera, Chardonnay, Gouais blanc, Nebbiolo, Pinot noir, Prosecco tondo, Ribolla gialla, Schiava bresciana, Schiava grossa, Schiava lombarda, Syrah, Traminer cultivars were analysed in this study. The samples were collected from the experimental station of Riccagioia scpa (Pavia - Italy), except for Gouais blanc, which was collected from the Agroscope collection (Changins - Swiss).

Gouais blanc, Ribolla gialla and Schiava samples were selected as cultivars sharing a possible common origin; Pinot noir and Traminer as second parents of some Gouais blanc progenies (Bowers et al., 2000); Chardonnay as progeny of Gouais blanc and Pinot noir (Bowers et al., 1999a); Bela Glera and Prosecco tondo as autochthonous Slovenian and Italian cultivars related to the growing area of Ribolla gialla (Štajner et al., 2008); and Barbera, Nebbiolo and Syrah as outgroups.

\section{Molecular analysis}

DNA extractions were performed with a DNeasy Plant Mini Kit (Qiagen, Courtaboeuf, France), starting at $0.02 \mathrm{~g}$ of dried young leaves. Microsatellite analyses were performed on 35 microsatellite markers (SSR): 20 SSR loci used in Laucou et al. (2011), except VVIV37, nine loci selected by the Vitis Microsatellite Consortium (VMC1e8, VMC2b3, VMC2b5, VMC2h4, VMC5a1, VMC5c1, VMC5c5, VMC5h2, VMC5h5), VrZag62, VrZag79, VrZag83 and VrZag93 (Sefc et al., 1999), and VVMD17, VVMD34 and VVMD36 (Bowers et al., 1999b). For Chardonnay cultivars, the allelic profile reported in Bowers et al. (1999a) was taken into account.

To investigate the relationship among Gouais blanc, Ribolla gialla and Traminer, an enhanced pedigree was performed at 23 additional SSR loci up to 58 SSR markers, as in Vouillamoz and Arnold (2010). 
PCR amplification conditions and capillary electrophoresis detection were carried out as reported in De Lorenzis et al. (2012).

\section{Data analyses}

GenAlEx 6.2 software (Peakall \& Smouse, 2006) was used to compare and identify samples with an identical allelic profile. The true-to-typeness for each sample was verified. Principal coordinates analysis (PCA, GenAlEx 6.2 software) was used to display genetic divergence among samples based on distance matrix. The dissimilarity matrix obtained by the first three principal coordinates was used to build a Neighbor-Joining dendrogram with MEGA 4.0 software (Tamura, 2007).
Relationship analyses were carried out on 58 SSR loci for Gouais blanc, Ribolla gialla and Traminer. The analyses were performed by calculating the number of loci with at least one allele identical by state (IBS), the identity by descent (IBD: $\Delta_{7}$ and $\Delta_{8}$ ) and relatedness $(r)$ coefficients. $\Delta_{7}, \Delta_{8}$ and $r$ coefficients were calculated by COANCESTRY 1.0 software (Wang, 2011). A total of 1000 bootstrapping samples were adopted to estimate the $95 \%$ confidence intervals. Allele frequencies were calculated based on the allelic profiles of 87 cultivars that were representative of the European germplasm (Josè Vouillamoz's SSR database, Swiss), genotyped at the same set of markers (data not shown).

TABLE 1

Allelic profiles at 35 SSR loci for identified genotypes.

\begin{tabular}{|c|c|c|c|c|c|c|c|c|c|c|c|}
\hline Locus & 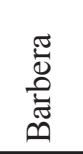 & $\frac{\pi}{\Phi} \frac{\pi}{0}$ & $\begin{array}{l}\frac{n}{\tilde{J}} \\
\stackrel{0}{\Xi} \\
0 \\
0\end{array}$ & $\begin{array}{l}\frac{0}{0} \\
\frac{0}{0} \\
0 \\
z\end{array}$ & 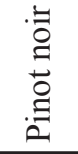 & 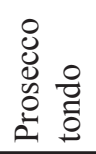 & 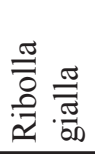 & 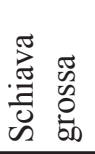 & 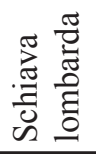 & 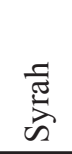 & 离 \\
\hline \multirow{2}{*}{ VMC1b11 } & 181 & 171 & 169 & 165 & 165 & 165 & 171 & 171 & 183 & 165 & 171 \\
\hline & 183 & 181 & 183 & 191 & 171 & 181 & 183 & 171 & 185 & 187 & 171 \\
\hline \multirow{2}{*}{ VMC1e8 } & 206 & 208 & 208 & 218 & 226 & 208 & 222 & 208 & 222 & 230 & 226 \\
\hline & 208 & 218 & 222 & 222 & 230 & 218 & 228 & 230 & 222 & 232 & 228 \\
\hline \multirow{2}{*}{ VMC2b3 } & 180 & 180 & 164 & 184 & 162 & 164 & 164 & 164 & 164 & 168 & 164 \\
\hline & 184 & 186 & 164 & 188 & 168 & 180 & 184 & 188 & 188 & 178 & 184 \\
\hline \multirow{2}{*}{ VMC2b5 } & 193 & 193 & 187 & 185 & 189 & 193 & 193 & 189 & 189 & 193 & 193 \\
\hline & 229 & 229 & 189 & 189 & 193 & 193 & 215 & 193 & 193 & 197 & 229 \\
\hline \multirow{2}{*}{ VMC2h4 } & 209 & 203 & 207 & 215 & 203 & 207 & 201 & 203 & $-^{\mathrm{a}}$ & 219 & 201 \\
\hline & 225 & 209 & 225 & 215 & 203 & 215 & 221 & 217 & $-{ }^{a}$ & 219 & 233 \\
\hline \multirow{2}{*}{ VMC4f3 } & 181 & 168 & 172 & 168 & 172 & 168 & 172 & 172 & 172 & 172 & 172 \\
\hline & 206 & 168 & 172 & 168 & 178 & 172 & 188 & 182 & 182 & 206 & 178 \\
\hline \multirow{2}{*}{ VMC5a1 } & 168 & 162 & 158 & 166 & 154 & 162 & 164 & 154 & 168 & 164 & 154 \\
\hline & 168 & 168 & 168 & 166 & 164 & 168 & 168 & 164 & 168 & 168 & 164 \\
\hline \multirow{2}{*}{ VMC5c1 } & 145 & 145 & 145 & 145 & 145 & 145 & 153 & 151 & $-^{\mathrm{a}}$ & 145 & 145 \\
\hline & 145 & 145 & 173 & 145 & 164 & 165 & 153 & 151 & $-^{\mathrm{a}}$ & 171 & 171 \\
\hline \multirow{2}{*}{ VMC5c5 } & 119 & 119 & 119 & 121 & 119 & 119 & 119 & 121 & 119 & 119 & 119 \\
\hline & 123 & 125 & 119 & 123 & 121 & 125 & 119 & 123 & 123 & 119 & 121 \\
\hline \multirow{2}{*}{ VMC5h2 } & 193 & 207 & 193 & 207 & 193 & 193 & 193 & 193 & $-^{\mathrm{a}}$ & 193 & 191 \\
\hline & 193 & 207 & 193 & 207 & 207 & 207 & 193 & 207 & $-{ }^{\mathrm{a}}$ & 207 & 193 \\
\hline \multirow{2}{*}{ VMC5h5 } & 176 & 176 & 178 & 176 & 168 & 172 & 170 & 168 & 178 & 178 & 170 \\
\hline & 194 & 194 & 194 & 188 & 178 & 176 & 194 & 188 & 194 & 194 & 178 \\
\hline \multirow{2}{*}{ VrZag62 } & 190 & 188 & 198 & 192 & 188 & 188 & 194 & 192 & 194 & 188 & 188 \\
\hline & 198 & 194 & 206 & 198 & 194 & 202 & 198 & 194 & 198 & 194 & 194 \\
\hline \multirow{2}{*}{ VrZag79 } & 241 & 249 & 235 & 241 & 235 & 245 & 235 & 237 & 237 & 241 & 241 \\
\hline & 255 & 257 & 241 & 249 & 241 & 255 & 247 & 257 & 247 & 247 & 247 \\
\hline \multirow{2}{*}{ VrZag83 } & 185 & 185 & 191 & 191 & 189 & 185 & 185 & 197 & 191 & 195 & 185 \\
\hline & 191 & 191 & 197 & 197 & 201 & 191 & 191 & 203 & 197 & 201 & 197 \\
\hline \multirow{2}{*}{ VrZag93 } & 189 & 199 & 189 & 189 & 189 & 197 & 189 & 189 & 189 & 189 & 189 \\
\hline & 229 & 199 & 189 & 189 & 189 & 199 & 189 & 189 & 189 & 199 & 225 \\
\hline \multirow{2}{*}{ VVIB01 } & 288 & 292 & 294 & 290 & 288 & 288 & 290 & 298 & 290 & 290 & 290 \\
\hline & 294 & 296 & 298 & 298 & 294 & 292 & 294 & 298 & 298 & 294 & 296 \\
\hline
\end{tabular}




\begin{tabular}{|c|c|c|c|c|c|c|c|c|c|c|c|}
\hline Locus & 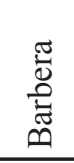 & $\frac{\pi}{0} \frac{\pi}{0}$ & 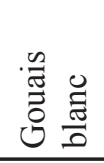 & $\begin{array}{l}0 \\
\frac{0}{0} \\
0 \\
00 \\
20 \\
\end{array}$ & 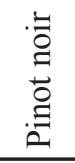 & 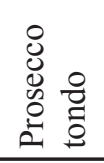 & 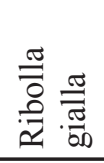 & 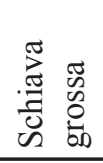 & 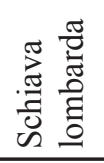 & 胥 & 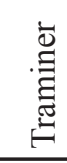 \\
\hline \multirow{2}{*}{ VVIH54 } & 166 & 168 & 150 & 166 & 166 & 166 & 166 & 168 & 168 & 162 & 160 \\
\hline & 168 & 176 & 168 & 180 & 168 & 176 & 168 & 168 & 178 & 166 & 166 \\
\hline \multirow{2}{*}{ VVIN16 } & 148 & 148 & 150 & 148 & 150 & 148 & 148 & 150 & 150 & 148 & 148 \\
\hline & 158 & 152 & 150 & 156 & 158 & 150 & 150 & 156 & 152 & 152 & 156 \\
\hline \multirow{2}{*}{ VVIN73 } & 262 & 262 & 262 & 262 & 262 & 262 & 262 & 264 & 262 & 260 & 262 \\
\hline & 262 & 262 & 262 & 262 & 264 & 262 & 262 & 264 & 262 & 262 & 262 \\
\hline \multirow{2}{*}{ VVIP31 } & 191 & 175 & 175 & 179 & 179 & 179 & 175 & 179 & 183 & 183 & 175 \\
\hline & 193 & 179 & 183 & 195 & 183 & 191 & 189 & 191 & 183 & 189 & 189 \\
\hline \multirow{2}{*}{ VVIP60 } & 318 & 320 & 320 & 316 & 318 & 320 & 320 & 316 & 320 & 314 & 304 \\
\hline & 320 & 320 & 320 & 320 & 320 & 326 & 320 & 320 & 330 & 316 & 320 \\
\hline \multirow{2}{*}{ VVIQ52 } & 79 & 76 & 76 & 83 & 83 & 76 & 76 & 79 & 76 & 81 & 79 \\
\hline & 83 & 87 & 83 & 83 & 83 & 83 & 79 & 85 & 85 & 83 & 83 \\
\hline \multirow{2}{*}{ VVIV67 } & 355 & 357 & 361 & 359 & 357 & 355 & 355 & 369 & 363 & 357 & 359 \\
\hline & 361 & 369 & 361 & 365 & 367 & 359 & 367 & 369 & 369 & 375 & 367 \\
\hline \multirow{2}{*}{ VVMD5 } & 224 & 224 & 232 & 230 & 226 & 224 & 230 & 234 & 228 & 224 & 230 \\
\hline & 224 & 244 & 238 & 234 & 236 & 244 & 232 & 236 & 236 & 230 & 236 \\
\hline \multirow{2}{*}{ VVMD7 } & 247 & 237 & 237 & 247 & 237 & 237 & 237 & 247 & 237 & 237 & 237 \\
\hline & 251 & 237 & 247 & 249 & 241 & 245 & 247 & 247 & 251 & 237 & 251 \\
\hline \multirow{2}{*}{ VVMD17 } & 211 & 221 & 221 & 211 & 211 & 221 & 221 & 221 & 221 & 211 & 221 \\
\hline & 219 & 221 & 223 & 221 & 221 & 221 & 221 & 221 & 221 & 223 & 221 \\
\hline \multirow{2}{*}{ VVMD21 } & 239 & 245 & 243 & 247 & 245 & 239 & 239 & 245 & 239 & 245 & 245 \\
\hline & 245 & 245 & 245 & 247 & 245 & 245 & 245 & 245 & 245 & 263 & 245 \\
\hline \multirow{2}{*}{ VVMD24 } & 205 & 205 & 205 & 205 & 213 & 209 & 205 & 209 & 209 & 205 & 205 \\
\hline & 213 & 213 & 205 & 209 & 215 & 213 & 205 & 213 & 213 & 209 & 213 \\
\hline \multirow{2}{*}{ VVMD25 } & 238 & 238 & 246 & 240 & 244 & 240 & 252 & 246 & 236 & 246 & 246 \\
\hline & 254 & 240 & 262 & 242 & 254 & 244 & 262 & 260 & 246 & 246 & 246 \\
\hline \multirow{2}{*}{ VVMD27 } & 183 & 177 & 177 & 181 & 183 & 177 & 177 & 179 & 179 & 185 & 183 \\
\hline & 187 & 177 & 179 & 185 & 187 & 191 & 183 & 183 & 183 & 187 & 191 \\
\hline \multirow{2}{*}{ VVMD28 } & 233 & 237 & 229 & 235 & 219 & 237 & 229 & 237 & 227 & 219 & 231 \\
\hline & 259 & 255 & 247 & 267 & 237 & 245 & 233 & 245 & 245 & 229 & 233 \\
\hline \multirow{2}{*}{ VVMD32 } & 250 & 252 & 250 & 240 & 240 & 262 & 250 & 256 & 254 & 240 & 240 \\
\hline & 270 & 264 & 270 & 262 & 270 & 264 & 250 & 270 & 270 & 272 & 270 \\
\hline \multirow{2}{*}{ VVMD34 } & 236 & 236 & 236 & 236 & 236 & 236 & 236 & 236 & 236 & 236 & 236 \\
\hline & 236 & 238 & 238 & 238 & 236 & 238 & 236 & 236 & 236 & 236 & 236 \\
\hline \multirow{2}{*}{ VVMD36 } & 249 & 249 & 271 & 259 & 261 & 247 & 271 & 271 & $-\mathrm{a}^{\mathrm{a}}$ & 261 & 249 \\
\hline & 249 & 249 & 283 & 259 & 261 & 249 & 271 & 303 & $\mathrm{a}^{\mathrm{a}}$ & 291 & 259 \\
\hline \multirow{2}{*}{ VVS2 } & 127 & 139 & 129 & 151 & 133 & 131 & 139 & 131 & 131 & 129 & 131 \\
\hline & 129 & 143 & 139 & 151 & 147 & 141 & 149 & 151 & 139 & 129 & 149 \\
\hline
\end{tabular}

a'-': missing data.

\section{RESULTS AND DISCUSSION}

\section{Genetic relationships}

A set of 35 SSR loci were used to genotype Barbera, Bela Glera, Gouais blanc, Nebbiolo, Pinot noir, Prosecco tondo, Ribolla gialla, Schiava bresciana, Schiava grossa, Schiava lombarda, Syrah and Traminer. Twelve unique allelic profiles were identified, and only Schiava bresciana and Schiava lombarda shared the same allelic profile. The SSR allelic profiles of the identified genotypes are listed in Table 1 . By comparing our results with DNA profiles published in previous works, the true-to-typeness of Barbera (This et al., 2004), Bela Glera (Štajner et al., 2008), Gouais blanc (Bowers et al., 1999a), Nebbiolo (Schneider et al., 2003), Pinot noir (Vouillamoz \& Grando, 2006), Prosecco tondo (Crespan et al., 2007), Ribolla gialla (Rusjan et al., 2010), Schiava grossa (Vouillamoz \& Arnold, 2010), Syrah (Vouillamoz 

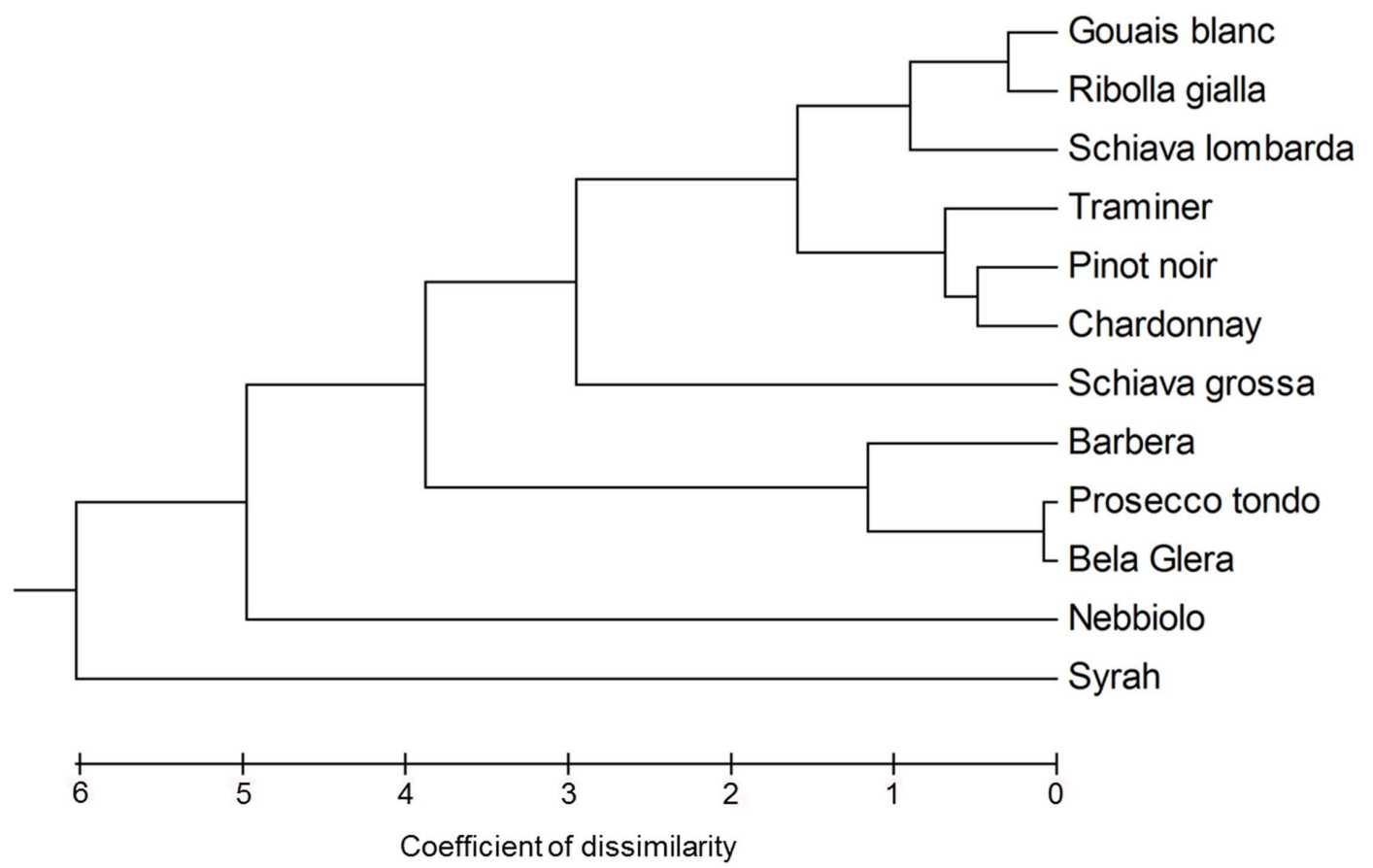

FIGURE 1

Neighbor-Joining dendrogram based on dissimilarity matrix of the first three PCA coordinates, showing the genetic relationship among 12 grapevine cultivars as determined by SSR data.

\& Grando, 2006) and Traminer (Regner et al., 2000) was ascertained. The allelic profiles of Schiava bresciana and Schiava lombarda did not match with any genotype in the available databases.

In order to understand the genetic similarity among cultivars, PCA was calculated based on the 35 SSR loci data matrix. The first three coordinates accounted for $68.18 \%$ of the total variation $(28.09 \%, 21.03 \%$ and $19.06 \%$, respectively). Based on the dissimilarity matrix obtained from the first three coordinates, a dendrogram displaying the relationship among samples was built (Fig. 1). The dendrogram showed two main clusters (threshold of dissimilarity value $=2$ ): i) the first one comprising Chardonnay, Gouais blanc, Pinot noir, Ribolla gialla, Schiava lombarda and Traminer; ii) the second one including Barbera and two varieties cultivated in the north-east of Italy and Slovenia, namely Bela Glera and Prosecco tondo. The other varieties were grouped in minor clusters. Inside the first main cluster, two very distinct subsets were identified: the first one including Gouais blanc, Ribolla gialla and Schiava lombarda, with the second one including Chardonnay, Pinot noir and Traminer. The Schiava grossa variety, clustered without any other samples, appeared to be related more to the first main cluster, while Nebbiolo and Syrah were grouped as outgroups. The dendrogram showed a clear genetic grouping of varieties largely consistent with their geographic origin. As expected, the molecular analysis highlighted the similarity among Gouais blanc, Ribolla gialla and one cultivar of "Schiava" (Schiava lombarda). This result was in agreement with the hypothesis of a common geographical origin for those varieties. The differences in the allelic profiles of the Schiava cultivars were confirmed, but the dissimilarity of these two genotypes was lower than expected if following the results obtained by Fossati et al.
(2001). Our results, based on the analysis of 35 SSR loci, could reject the Fossati et al. (2001) hypothesis that the term "Schiave" more likely refers to a similarity in the vine training system than to a similar genetic background. The latter hypothesis was based on an analysis of only five SSR loci and five AFLP primers combinations, which are known sometimes to produce irreproducible AFLP-banding profiles (Benjak et al. 2006).

Furthermore, the dendrogram grouped together the Gouais blanc, Ribolla gialla and Schiava lombarda cultivars, which share some phenotypic and oenological traits: high vigour and high-yielding capacity, large berries and bunches, and medium sugar and high acidity levels in the berry juice (O. Failla, personal communication, 2013). A further indication of the common origin of Gouais blanc and Schiava is linked to the semantics of the variety name. In Germany, the medieval term "Heunisch" was used to identify the local wines in contrast to "Fränkisch" (foreign wine). "Heunisch" and "Schiava" appear to have the same semantic value: "Heunisch" - "Hunnisch" i.e. Huns'; and "Schiava" - "Slavus" i.e. Slavic (from Slavonia), two old populations coming from Eastern Europe (Scienza \& Failla, 1996). Following the Venetian meaning of the term "Slavus", the Slavs in particular were considered to be the populations coming from the Northern Balkans.

Moreover, the second main cluster showed a consistent relationship with geographical area. In this cluster we find Bela Glera and Prosecco tondo strongly related to Friuli Venezia Giulia (the Italian region), Istria and Slovenia. Both names sometimes were used erroneously to identify the same variety (Crespan et al., 2007). The name Prosecco tondo could have arisen from the village of Prosecco (Trieste, Friuli Venezia Giulia), and its synonyms are Teran Bijeli in Croatia 
(Maletić et al., 1999), and Briška Glera and Števerjana in Slovenia (Štajner et al., 2011). Varieties called "Glera" are cultivated in Italy (Cividale and Tieste) and in neighbouring countries (Crespan et al., 2009; Rusjan et al., 2010). The allelic profile of Bela Glera was genetically dissimilar to the other Glera/Prosecco tondo allelic profiles reported in previous works (Štajner et al., 2008; Crespan et al., 2009; Rusjan et al., 2010). This dissimilarity could be explained by the use of the word "Glera" to identify a group of white grapevine varieties (Vertovec, 1844). What was surprising was the presence of Barbera, one of the most important red grape varieties grown in the north-west of Italy, in the third cluster.

Two varieties largely cultivated in the Alpine Arc, Nebbiolo and Syrah, were grouped as an outgroup. Nebbiolo is considered one of the noblest Italian varieties, and its growing area is limited to the mountains of Valle d'Aosta, Piemonte and Valtellina, while Syrah is the famous Rhone Valley red grape cultivar cultivated worldwide. The dissimilarity between the first main cluster and the outgroup varieties was consistent with the genetic distance between Pinot noir and Syrah proved by Vouillamoz and Grando (2006).

\section{Kinship analysis}

Considering the broad participation of Gouais blanc and Traminer in the parentship, origin and spread of the grape landraces, Ribolla gialla could be considered a good candidate for having a strong relationship with these two varieties. In order to investigate a possible relationship between Gouais blanc, Ribolla gialla and Traminer, 58 SSR loci were used to generate a deep genotyping and to suggest the most likely pedigree among these varieties. The allelic profile of each analysed cultivar is listed in Table 2.

Gouais blanc and Ribolla gialla shared at least one allele for locus 53 out of 58 loci (IBS = 53), and the IBD and relatedness coefficients values were: $\Delta_{7}=-0.0610 \pm 0.0145$; $\Delta_{8}=0.5031 \pm 0.0377$; and $r=0.1905 \pm 0.0023$ respectively. These results are not typical of the PO (parent-offspring) relationship, as the IBS value should have been $58(100 \%$ of analysed loci) and the IBD and $r$ values should have been close to the theoretical values 0,1 and 0.5 . The putative PO relationship between Gouais blanc and Ribolla gialla can be ruled out, because it would seem improbable that five discrepancies can be explained by mutations, null alleles or PCR errors (Vouillamoz \& Grando, 2006). Nevertheless, these values could explain a second-degree relationship.

At the same time, the supposed close relationship

TABLE 2

Allelic profiles of 23 additional SSR loci for Gouais blanc, Ribolla gialla and Traminer cultivars. Reference variety: 'Pinot noir'.

\begin{tabular}{|c|c|c|c|c|}
\hline Locus & Gouais blanc & Ribolla gialla & Traminer & Pinot Noir \\
\hline \multirow{2}{*}{ VMC1c10 } & 142 & 156 & 156 & 156 \\
\hline & 168 & 168 & 168 & 156 \\
\hline \multirow{2}{*}{ VMC2a5 } & 157 & 157 & 157 & 189 \\
\hline & 171 & 171 & 189 & 189 \\
\hline \multirow{2}{*}{ VMC2b11 } & 184 & 168 & 168 & 180 \\
\hline & 184 & 184 & 180 & 182 \\
\hline \multirow{2}{*}{ VMC2e7 } & 152 & 156 & 152 & 152 \\
\hline & 156 & 160 & 160 & 158 \\
\hline \multirow{2}{*}{ VMC2f10 } & 97 & 93 & 93 & 93 \\
\hline & 99 & 99 & 103 & 115 \\
\hline \multirow{2}{*}{ VMC3d12 } & 198 & 205 & 198 & 205 \\
\hline & 205 & 205 & 205 & 222 \\
\hline \multirow{2}{*}{ VMC4c6 } & 157 & 163 & 163 & 163 \\
\hline & 163 & 165 & 165 & 163 \\
\hline \multirow{2}{*}{ VMC5g8 } & 303 & 303 & 313 & 313 \\
\hline & 311 & 317 & 317 & 317 \\
\hline \multirow{2}{*}{ VMC6e1 } & 141 & 165 & 151 & 151 \\
\hline & 165 & 170 & 161 & 165 \\
\hline \multirow{2}{*}{ VMC6e10 } & 91 & 109 & 109 & 107 \\
\hline & 107 & 132 & 113 & 109 \\
\hline \multirow{2}{*}{ VMC6g1 } & 198 & 191 & 170 & 170 \\
\hline & 198 & 198 & 170 & 178 \\
\hline \multirow{2}{*}{ VMC8d11 } & 136 & 126 & 132 & 122 \\
\hline & 142 & 136 & 136 & 132 \\
\hline
\end{tabular}


TABLE 2 (CONTINUED)

\begin{tabular}{|c|c|c|c|c|}
\hline Locus & Gouais blanc & Ribolla gialla & Traminer & Pinot Noir \\
\hline \multirow{2}{*}{ VMC8f10 } & 197 & 205 & 197 & 195 \\
\hline & 205 & 233 & 233 & 197 \\
\hline \multirow{2}{*}{ VMC8g6 } & 147 & 147 & 155 & 147 \\
\hline & 155 & 155 & 169 & 169 \\
\hline \multirow{2}{*}{ VMC9b5 } & 248 & 244 & 242 & 244 \\
\hline & 262 & 250 & 244 & 248 \\
\hline \multirow{2}{*}{ VMC16f3 } & 177 & 177 & 177 & 177 \\
\hline & 181 & 177 & 183 & 183 \\
\hline \multirow{2}{*}{ VrZag21 } & 202 & 202 & 200 & 200 \\
\hline & 206 & 215 & 206 & 206 \\
\hline \multirow{2}{*}{ VrZag29 } & 112 & 112 & 112 & 112 \\
\hline & 112 & 116 & 116 & 116 \\
\hline \multirow{2}{*}{ VVMD6 } & 194 & 194 & 205 & 205 \\
\hline & 214 & 212 & 212 & 205 \\
\hline \multirow{2}{*}{ VVMD26 } & 249 & 249 & 249 & 249 \\
\hline & 251 & 249 & 251 & 255 \\
\hline \multirow{2}{*}{ VVMD31 } & 212 & 210 & 204 & 216 \\
\hline & 214 & 212 & 216 & 216 \\
\hline \multirow{2}{*}{ VVS4 } & 168 & 168 & 151 & 168 \\
\hline & 168 & 168 & 151 & 173 \\
\hline \multirow{2}{*}{ VVS29 } & 171 & 171 & 171 & 171 \\
\hline & 179 & 179 & 171 & 179 \\
\hline
\end{tabular}

between Ribolla gialla and Traminer has to be dismissed. Ribolla gialla is genetically dissimilar to Traminer, sharing only 47 out of 58 analysed loci. The IBD and $r$ coefficient values calculated for these pair of varieties do not match the theoretical values of the assignment of kinship categories $\left(\Delta_{7}\right.$ $=-0.1675 \pm 0.0732 ; \Delta_{8}=0.3281 \pm 0.0165 ; r=-0.0035 \pm$ 0.0282 ), suggesting that Ribolla gialla and Traminer could be third or more distant relatives. These data provide strong evidence that Ribolla gialla is not a progeny of 'Gouais blanc $\mathrm{x}$ Traminer'.

\section{CONCLUSIONS}

During the process of domestication, the role of winegrowers was to improve the quality and quantity of the production of grapes by selecting seedlings from spontaneous crosses among different domesticated forms of $V$. vinifera subsp. sativa, and possible also among its wild relative forms of $V$. vinifera subsp. sylvestris. Gouais blanc has played an important role in the origin of the main grapevines of Central Europe, as is evident from several published research works providing information on the Gouais blanc progeny. Although the hypothesis that Ribolla gialla is a full sibling of two ancient cultivars widely involved in the history of grape breeding (Gouais blanc and Traminer) has been rejected, the genetic data suggest a high correlation among Ribolla gialla, Gouais blanc and the Schiava cultivars. Right now we are not able to determine the hierarchy of or identify the missing links among these varieties, but our results have highlighted the first evidence of a common ancestral variety and the possible sympatric origin of these grapevines in EasternCentral Europe.

\section{LITERATURE CITED}

Aeberhard, M., 2005 ( $1^{\text {st }}$ ed). Geschichte der alten Traubensorten: Ein historisch-ampelographischer Rückblick, Aarcadia Verlag, Solothurn.

Bacilieri, R., Lacombe, T., Le Cunff, L., Di Vecchi-Staraz, M., Laucou, V., Genna, B., Péros, J.P., This, P. \& Boursiquot, J.M., 2013. Genetic structure in cultivated grapevines is linked to geography and human selection. BMC Plant Biol. doi: 10.1186/1471-2229-13-25

Benjak, A., Konradi, J., Blaich, R. \& Forneck, A., 2006. Different DNA extraction methods can cause different AFLP profiles in grapevine (Vitis vinifera $\mathrm{L}$.). Vitis $45,15-21$.

Boursiquot, J.M., Lacombe, T., Laucou, V., Julliard, S., Perrin, F.X., Lanier, N., Legrand, D., Meredith, C. \& This P., 2009. Parentage of Merlot and related winegrape cultivars of southwestern France: Discovery of the missing link. Aus. J. Grape Wine Res. 15, 144-155.

Bowers, J.E., Boursiquot, J.M., This, P., Chu, K., Johansson, H. \& Meredith, C.P., 1999a. Historical genetics: The parentage of Chardonnay, Gamay and other wine grapes of northeastern France. Science 285, 1562-1565.

Bowers, J.E., Dangl, G.S. \& Meredith, C.P., 1999b. Development and characterization of additional microsatellite DNA markers for grape. Am. J. Enol. Vitic. 50, 243-246.

Bowers, J.E., Siret, R., Meredith, C.P., This, P. \& Boursiquot, J.M., 2000. A single pair of parents proposed for a group of grapevine varieties in Northeastern France. Acta Horticulturae 528, 129-132. 
Calò, A. \& Costacurta, A., 2004 ( $1^{\text {st }}$ ed). Dei vitigni italici. Ovvero delle loro storie, caratteri e valorizzazione. Matteo, Treviso.

Calò, A., Scienza, A. \& Costacurta, A., 2006 ( $1^{\text {st }}$ ed). Vitigni d'Italia. Edagricole, Bologna.

Cipriani, G., Spadotto, A., Jurman, I., Di Gaspero, G., Crespan, M., Meneghetti, S., Frare, E., Vignani, R., Cresti, M., Morgante, M., Pezzotti, M., Pe, E., Policriti, A. \& Testolin, R., 2010. The SSR-based molecular profile of 1005 grapevine (Vitis vinifera L.) accessions uncovers new synonymy and parentages, and reveals a large admixture amongst varieties of different geographic origin. Theor. Appl. Genet. 121, 1569-1585.

Cosmo, I. \& Polsinelli, M., 1957 ( $1^{\text {st }}$ ed). Ribolla gialla. Annali della sperimentazione agraria, Roma.

Cosmo, I. \& Polsinelli, M., 1962 ( $1^{\text {st }}$ ed). Commissione per lo studio ampelografico dei principali vitigni ad uve da vino coltivati in Italia. Ministero dell'Agricoltura e delle Foreste, Roma.

Crespan, M., Cancellier, S., Chies, R., Giannetto, S., Meneghetti, S. \& Costacurta, A., 2009. Molecular contribution to the knowledge of two ancient varietal populations: 'rabosi' and 'glere'. Acta Horticulturae 827, 217-220.

Crespan, M., Crespan, G., Giannetto, S., Meneghetti, S. \& Costacurta A., 2007. 'Vitouska' is the progeny of 'Prosecco tondo' and 'Malvasia bianca lunga'. Vitis 46, 192-194.

De Lorenzis, G., Imazio, S., Biagini, B., Failla, O. \& Scienza, A., 2012. Pedigree reconstruction of the Italian grapevine Aglianico (Vitis vinifera L.) from Campania. Mol. Biotechnol. doi: 10.1007/s12033-012-9605-9

De Lorenzis, G., Imazio, S., Rusjan, D., Vouillamoz, J.F., Nikolaou, N., Failla, O. \& Scienza, A., 2013. Genetic investigation of grapevine varieties 'Ribolla Gialla' (Italy), 'Rebula' (Slovenia) and 'Robola' (Ionian Islands). Scientia Horticulturae 150, 425-431.

Forni, G., 2012. The origin of "Old World" viticulture. In: Maghradze, D., Rustioni, L., Scienza, A., Turok, J. \& Failla, O. (eds). Caucasus and Northern Black Sea Region. Vitis, Special Issue, 27-38.

Fossati, T., Labra, M., Castiglione, S., Failla, O., Scienza, A. \& Sala, F., 2001. The use of AFLP and SSR molecular markers to decipher homonyms and synonyms in grapevine cultivars: The case of the varietal group known as "Schiave". Theor. Appl. Genet. 102, 200-205.

Imazio, S., Maghradze, D., De Lorenzis, G., Bacilieri, R., Laucou, V., This, P., Scienza, A. \& Failla O., 2013. From the cradle of grapevine domestication: Molecular overview and description of Georgian grapevine (Vitis vinifera L.) germplasms. Tree Genetics and Genomes. doi: 10.1007/ s11295-013-0597-9

Lacombe, T., Boursiquot, J.M., Laucou, V., Di Vecchi-Staraz, M., Péros, J.P. \& This, P., 2012. Large-scale parentage analysis in an extended set of grapevine cultivars (Vitis vinifera L.). Theor. Appl. Genet. doi: 10.1007/ s00122-012-1988-2

Laucou, V., Lacombe, T., Dechesne, F., Siret, R., Bruno, J.P., Dessup, M., Dessup, T., Ortigosa, P., Parra, P., Roux, C., Santoni, S., Varés, D., Pèros, J.P., Boursiquot, J.M. \& This, P., 2011. High throughput analysis of grape genetic diversity as a tool for germplasm collection management. Theor. Appl. Genet. 122, 1233-1245.

Maletić, E., Sefc, K.M., Steinkellner, H., Kontić, J.K. \& Pejić, I., 1999. Genetic characterization of Croatian grapevine cultivars and detection of synonymous cultivars in neighboring regions. Vitis $38,79-83$.

Olmo, H.P., 1995 ( $2^{\text {nd }}$ ed). Grapes. Longman, London.

Peakall, R. \& Smouse, P.E., 2006. GENALEX 6: GENETIC analysis in Excel. Population genetic software for teaching and research. Mol. Ecol. Notes 6, 288-295.
Peterlunger, E., Zurlini, L., Crespan, G., Colugnati, G. \& Del Zan, F., 2004. Friuli Venezia Giulia. In: Del Zan, F., Failla, O. \& Scienza, A. (eds). La vite e l'uomo dal rompicapo delle origini al salvataggio delle relique, vol I. ERSA - Agenzia Regionale per lo Sviluppo Rurale, Gorizia. pp. 769 - 852.

Regner, F., Stadlhuber, A., Eisenheld, C. \& Kaserer, H., 2000. Considerations about the evolution of grapevine and the role of Traminer. Acta Horticulturae $528,179-184$

Rusjan, D., Jug, T. \& Štajner, N., 2010. Evaluation of genetic diversity: Which of the varieties can be named 'Rebula' (Vitis vinifera L.)? Vitis 49, 189-192.

Scienza, A., 1999. Cosa significa la definizione: "Vitigni antichi". In: Scienza. A. \& Valenti, L. (eds). Vitigni antichi della Lombardia, vol I. Provincia di Pavia, Pavia. pp. $11-34$.

Scienza, A. \& Failla, O., 1996 ( $1^{\text {st }}$ ed $)$. La circolazione dei vitigni in ambito Padano-Veneto ed Atesino: le fonti storico-letterarie e l'approccio biologico-molecolare. Istituto Trentino del Vino, Trento.

Schneider, A. \& Mannini, F., 2006 (1st ed). Vitigni del Piemonte, varietà e cloni. Regione Piemonte, Tipolito Subalpina.

Schneider, A., Boccacci, P. \& Botta, R., 2003. Genetic relationships among grape cultivars from North-Western Italy. Acta Horticulturae 603, 229-233.

Sefc, K.M., Regner, F., Turetschek, E., Glossl, J. \& Steinkellner, H., 1999. Identification of microsatellite sequences in Vitis riparia and their applicability for genotyping of different Vitis species. Genome 42, 367-373.

Štajner, N., Korosec-Koruza, Z., Rusjan, D. \& Javornik, B., 2008. Microsatellite genotyping of old Slovenian grapevine varieties (Vitis vinifera L.) of the Primorje (coastal) winegrowing region. Vitis 47, 201-204.

Štajner, N., Rusjan, D., Korošec-Koruza, Z. \& Javornik, B., 2011. Genetic characterization of old Slovenian grapevine varieties of Vitis vinifera L. by microsatellite genotyping. Am. J. Enol. Vitic. 62, 250-255.

Tamura, K., Dudley, J., Nei, M. \& Kumar, S., 2007. MEGA4: Molecular Evolutionary Genetics Analysis (MEGA) software version 4.0. Mol. Biol. Evol. 24, 1596-1599.

This, P., Jung, A., Boccacci, P., Borrego, J., Botta, R., Costantini, L., Crespan, M., Dangl, G.S., Eisenheld, C., Ferreira-Monteiro, F., Grando, S., Ibáñez, J., Lacombe, T., Laucou, V., Magalhães, M., Meredith, C.P., Milani, N., Peterlunger, E., Regner, F., Zulini, L. \& Maul, E., 2004. Development of a standard set of microsatellite reference alleles for identification of grape cultivars. Theor. Appl. Genet. 109, 1448-1458.

This, P., Lacombe, T. \& Thomas, M.R., 2006a. Historical origin and genetic diversity of wine grapes. Trends Genet. 22, 511-519.

This, P., Siret, R., Lacombe, T., Moreau, R.F., Vares, D. \& Boursiquot J.M., 2006b. Grape and wine varietal authentication by DNA analysis. Acs symposium series, USA. doi: 10.1021/bk-2007-0952.ch014

Vertovec, M., 1844 ( $1^{\text {st }}$ ed). Vinoreja. Agroind Vipava, Vipava.

Vouillamoz, J.F. \& Arnold, C., 2010. Microsatellite pedigree reconstruction provides evidence that 'Müller-Thurgau' is a grandson of 'Pinot' and 'Schiava Grossa'. Vitis 49, 63-65.

Vouillamoz, J.F. \& Grando, M.S., 2006. Genealogy of wine grape cultivars: Pinot is related to Syrah. Heredity 97, 102-110.

Wang, J., 2011. COANCESTRY: A program for simulating, estimating and analysing relatedness and inbreeding coefficients. Mol. Ecol. Resources 11, 141-145.

Zohary, D. \& Hopf, M., 2000 ( $3^{\text {rd }}$ ed). Domestication of plants in the old world. Oxford University Press, Oxford. 